\title{
Some Thoughts on the Japanese Major Education of Chinese Colleges in the Transition Period
}

\author{
Wei Zou \\ Xi'an University, Xi'an, Shanxi, China, 710065 \\ zouwei2003@126.com
}

\begin{abstract}
Keywords: China; Colleges and universities; Professional Japanese; Subject; Transitional period; Countermeasures
\end{abstract}

\begin{abstract}
After more than ten years of rapid development, Japanese teaching in China's universities has ushered in the new period of transformation. With the rapid increase of the number of students, teachers and scientific research level, ivory tower education begins to coexist with applied education. Facing the future, we must re-examine the new topics in the transition period. It is needed to transfer from the cultivation of language ability and language communicative ability to the cultivation of intercultural communication ability by using Japanese, from the purpose of learning Japanese to the aim of mastering professional knowledge and skills related to Japanese study, and also shift from cultivating students' ability to do job related to Japanese to cultivate students' ability to adapt to any related work. At the same time, it is necessary to re-examine the Japanese teaching task in the basic period, giving full play to the students' autonomous learning and collaborative learning ability. Based on the exploration of Japanese education with Chinese characteristics and the study of Japanese language and literature, teacher should participate in a wider range of scientific studies, such as the study of Japanese culture and society. In the transformation period, the professional Japanese of colleges has to solve many problems, so it must face the challenges to seek new development.
\end{abstract}

\section{Introduction}

After entering the 21 st century, Chinese society has stepped into a new period of transformation. And after the rapid development in the recent ten years, Japanese majors in China's higher education has also entered an unusual period: unprecedented scale of running school, the rapid increase of the number of students, rapid growth of the level of teachers and scientific research, coexistence of ivory tower education and applied education, increasingly fierce competition for employment, uneven development of teaching quality, equal importance of teachers' teaching and scientific research, the heavier pressure, etc. That is to say, Japanese major is facing a new transitional period [1]. Professional Japanese teaching is for future development, so it is needed to re-examine the development situation of Japanese major, to solve new subjects like Japanese talent cultivation, teaching reform, teachers' team construction, and scientific research and so on. This essay intends to think about the problems related to Japanese major of colleges in the transitional period, and also to put forward new issues and countermeasures for the future development of Japanese major, for reference to the Japanese industry colleagues [2].

\section{Japanese Professional Educations in Chinese Higher Education Have Stepped to the Transitional Period.}

Introduction to the Background of the Transitional Period. Since 1999, with the overall development of Chinese universities and colleges, Japanese major, especially Japanese professional education of undergraduate schools has entered into a fast lane with rapid development. Xiugang (2008) introduced the development trace of Japanese major from many aspects, such as the increase of undergraduate majors and master degree programs, the formulation of Japanese teaching syllabus, the implementation of Japanese TEM-4 and TEM-8 examination, teaching method and the teaching method reform, unbalanced Japanese teaching quality, the contradiction between guidance teachers 
of Japanese graduation thesis and student's selection of topics, etc. [3]

The Concrete Embodiment of Japanese Professional Education in Chinese Higher Education. The number of undergraduate colleges opening up Japanese major has increased nearly 200 in less than 10 years, mainly in Jiangsu, Zhejiang, Shandong, Guangdong and other places. The number of student enrollment is mainly from the independent colleges, at the same time the enrollment of some independent colleges which have just set up is five times their parent schools. In addition, according to information released by the Ministry of Education about the major catalogue of undergraduate colleges and universities and the data of colleges opening the major, in 2010, the number of colleges opening Japanese major has reached 466, ranked the top 12 in the number of colleges opening a major. And based on the list of colleges who have enrollment qualification released by the Ministry of Education in 2011, the number of undergraduate schools is 820 (including private schools), and 311 independent colleges have been established with approval, a total of 1131, while the colleges opening Japanese major account for 41.2\%, as shown in Figure 2.1 below[5].

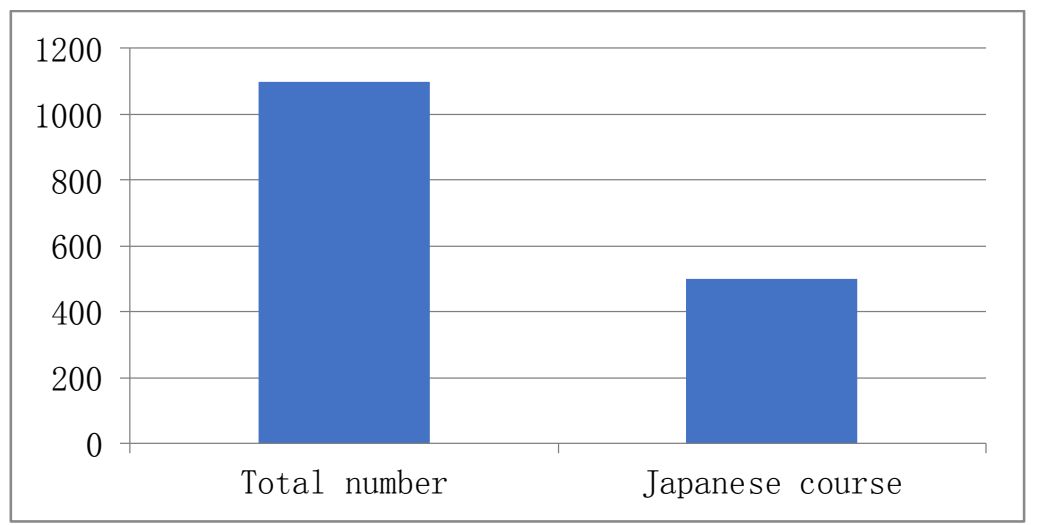

Figure 2.1. Statics on Japanese course in domestic undergraduate colleges

According to the catalogue of specialty, currently, in the aspects of opening numbers, the top ten foreign majors are English (935), Japanese (466), Russian (118), Korean (102), French (92), German (86), Spain (32), Thai (14), Vietnamese (14), as shown in Figure 2.2. It can be seen that in foreign language major, although Japanese major is inferior to English major, it is far more than other majors like Russian, Korean, French, German, etc. ${ }^{[6]}$ At the same time, the types and quantity of textbooks, the opening frequency of international conferences related to Japanese, and also the number of qualified teachers and lessons has developed a lot. The scale of the training of Japanese teachers and authority activities like teachers' basic skills contest, various types of Japanese speech contest, thesis competition authority activities are far more than that of languages other than English. In this sense, Japanese majors can longer be regarded as "small language", but "big language" or "big major".

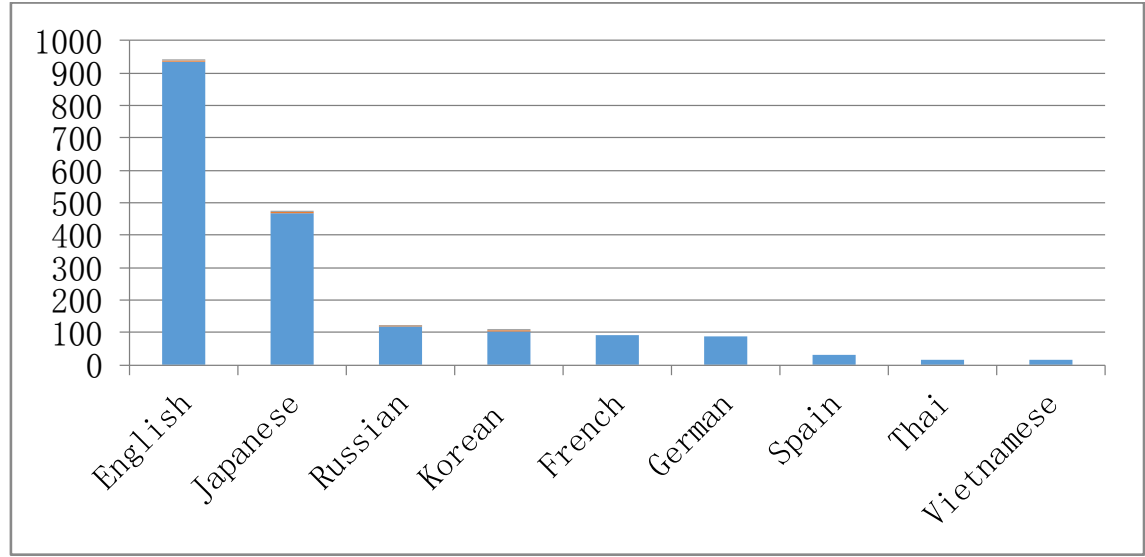

Figure 2.2. Statics on the number of colleges opening foreign language majors 


\section{The Transformation of Japanese Professional Talent Training Objectives}

Concept Introduction. Professional Japanese teaching in the transition period must start from the transformation of talent training objectives. Cultivating high-quality foreign language talents with good thought quality, professional quality, cultural quality, and physical and psychological quality talents is the general requirement of foreign language majors, but owing to the future fierce competition of talents, Japanese major must change in two aspects. One is the talents cultivation of intercultural communication, and the second is the cultivation of talents with Japanese plus alpha ability. Improving the ability of the two aspects can help Japanese professional graduates not only to be able to engage in the work related to the Japanese, but also be able to do more extensive work.

\section{The Important Stage of Chinese Japanese Education}

China's Japanese language education, as with other foreign languages, has experienced two important stages in the professional training objectives and ushered in the third important stage.

The first stage is before the reform and opening-up, due to the number of training, teachers and other reasons, the focus of teaching is the listening, speaking, reading, writing, translation and other language abilities of students, especially the ability to read and translate. The second stage mainly focuses on cultivating students' ability to use language to communicate. Applying Japanese to communication is the goal of Japanese learning, paying attention to students' communicative competence, especially the enhancement of students' spoken language ability. However, at this stage, the focus is to cultivate students' intercultural communication competence with the use of Japanese [7].

In the transition period, Japanese talents should have good ideological and political quality, cultural quality, physical and psychological quality, the intercultural communicative competence with the use of Japanese, and also "Japanese + alpha" ability. These talents will not only the winner of Japanese talent competition, but also they will become strong competitors in the wider profession competition.

\section{Japanese Education Reforms in the Transition Period}

The Necessity of Education Reform. Since the goal of Japanese talents training in transitional period has changed, there must be new requirements about Japanese teaching, such as the reform of teaching schedule, Japanese teaching content, teaching means, etc. Therefore, education reform is imminent.

The period of transition is not a short time, and the new talents training programs can be finished immediately but need a long process. However, the schools who start thinking first and dare to challenge will become the first beneficiaries of the teaching reform, while those walking in the final will be eliminated [8].

Specific Measures for Education Reform. For teaching arrangement, we must re-examine the arrangement of Japanese teaching in the basic stage, regarding the cultivation of students' intercultural communicative ability as the main purpose. At the same time, the cultivation of students' Alpha ability also needs much attention. Therefore, the Japanese teaching in basic stage has become the key, to put the most elite teaching force on teaching in the foundation stage, and also increase the difficulty of teaching in the basic stage.

The Significance of Educational Reform. To ensure the transformation of talent training goal, new strides must be taken in the aspect of teaching reform. In particular, the position and function of basic Japanese teaching should be re-examined. Dare to face contradictions like less lessons, big class capacity and so on, making full use of Internet and multimedia technology etc., giving full play to the time and space inside and outside the classroom or school to cultivate students' autonomous learning and collaborative learning ability. Only to solve language learning and basic intercultural communicative competence problems in the basic stage can the mastery of professional knowledge and skills by Japanese learning in senior stage be achieved [9]. 


\section{The Construction of Professional Japanese Teachers in the Transition Period}

Necessities. With clear objectives and establishment of teaching reform directions, the key is whether the teachers' team construction is keeping up with the pace of personnel training and teaching reform in the transition period. The enhancement of intercultural communicative competence and cultivation of Japanese plus alpha ability has put forward higher scientific research requirements on Japanese teachers. The research scope of Japanese teachers will be extended to wider areas of Japanese research, which makes Japanese language teachers not only be teachers but also scholars. This is the need of Japanese personnel training, and also the need of Japanese teachers to adapt to the requirements of the liberal arts teachers.

Concrete Measures. Firstly, we should study Japanese teaching reform, combining the latest theory of domestic and foreign researches on foreign language teaching with the practice of Japanese education closely, to explore effective ways for Chinese people to learn Japanese. Especially, it is needed to explore the establishment of Japanese teaching system with Chinese characteristics which takes Chinese or adults as objects according to the reality of Chinese undergraduates. For example, how to utilize Chinese characters which are familiar to Chinese to learn vocabulary well, how to use Chinese classic to conduct intercultural education, how to use most students' English learning experience and Chinese learning experience in the middle school or high school, etc. Teachers should master the most advanced teaching means, making students to form a habit of autonomous learning and subjective learning, so as to help them learn well [10].

The enhancement of intercultural communication competence and Japanese plus alpha ability has presented new challenges for Japanese teaches. Japanese teachers with a good mastery of Japanese language and literature are needed, so do Japanese educators who are familiar with Japanese social culture, Japanese politics and Japanese economy, etc. As a result, we should make quite a portion of teachers be able to teach students Alpha ability through Japanese teaching [11].

\section{Conclusions}

The above passage has discussed several important problems of undergraduate professional Japanese education in the transition period. First, with the increase or decrease of Japanese majors and the changes of the country's demand for talent, Japanese has become "big major" owing to its large opening number and students. "Big major" is the significant symbol of Japanese in the transition period. In this stage, the fierce competition among students for jobs will actually become the struggle of Japanese major for existence, so we must begin to think about the future of professional Japanese teaching and make plans. Teaching contents and teaching arrangements should be helpful to the cultivation of Japanese talents, to make full use of modern means of teaching, to develop students' autonomous learning and subjective learning ability, which is a great event that can be regarded as the revolution of teaching methods. As the executors of education, teachers should possess intercultural communicative competence, exploring teaching methods which are beneficial for Chinese students to master both skills, at the same time, teachers should participate in the study of Japanese problems, making themselves become the main force in the comparative study and cross-cultural research.

Owing to the differences in schools, regions and quality of students, the objectives of natural talent training and reform pace are also different, but when facing new challenges, we must have new thinking. In the transition period, there are a lot of problems to be solved which are related to professional Japanese of colleges, so do the challenges, so we must think more deeply, and make contributions to speeding up the reform in order to create new glories.

\section{References}

[1] Yan X, Jian C, Nian-nian L, et al: Journal of Jiamusi Education Institute, 2014, 2: 015.

[2] Kashiwaya K, Saga T, Ishii Y, et al: Journal of Infection and Chemotherapy, 2016, 22(6): 407-413. 
[3] Luan Z: The Science Education Article Collects, 2013, 10: 078.

[4] Imaki J. Anatomy of Composition: How are Japanese Compositions Evaluated?[D]. Australian National University, 2014.

[5] Yang J: The World and Chongqing, 2014, 7: 021.

[6] Yan H: Journal of Huaihai Institute of Technology (Humanities \& Social Sciences Edition), 2013, 7: 021.

[7] Turner M: Japanese Studies, 2013, 33(3): 315-330.

[8] Janjua N: Journal of medical English education: official journal of Japan Society for Medical English Education, 2014, 13(1): 7-14.

[9] Xiao-bing Z: Journal of Jincheng Institute of Technology, 2012, 3: 016.

[10] McLelland M: electronic journal of contemporary japanese studies, 2013.

[11] Heffernan N: Methodologies for Effective Writing Instruction in EFL and ESL Classrooms, 2014: 131. 